\section{Cyclical caspofungin for chronic pulmonary aspergillosis in sarcoidosis}

\begin{abstract}
In sarcoidosis, chronic pulmonary aspergillosis (CPA) may be associated with significant morbidity, and treatment failure rates are often high, even with newer triazole antifungal agents. We report a treatment regimen of cyclical caspofungin infusions in 10 patients with sarcoidosis and worsening CPA despite oral triazoles.
\end{abstract}

Chronic pulmonary aspergillosis (CPA, including aspergilloma) complicates 3-12\% of cases of sarcoidosis $^{1}$, and treatment failure rates remain high, even with newer triazole antifungals. ${ }^{2-5}$ We report a successful treatment regimen of cyclical caspofungin infusions in patients with sarcoidosis and worsening CPA despite oral triazoles.

Sarcoidosis and CPA were diagnosed in accordance with published criteria (described in the online supplement). Ten patients (six men; mean age $43.9 \pm 9.0$ years) received treatment with caspofungin

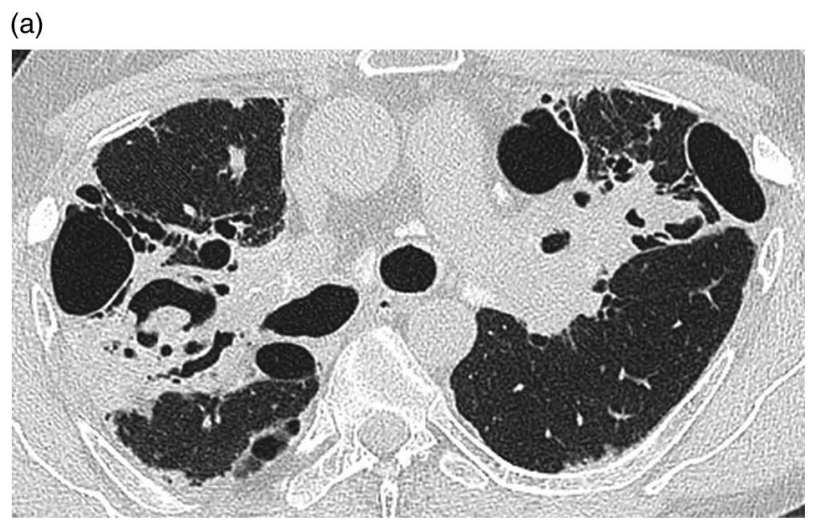

(b)

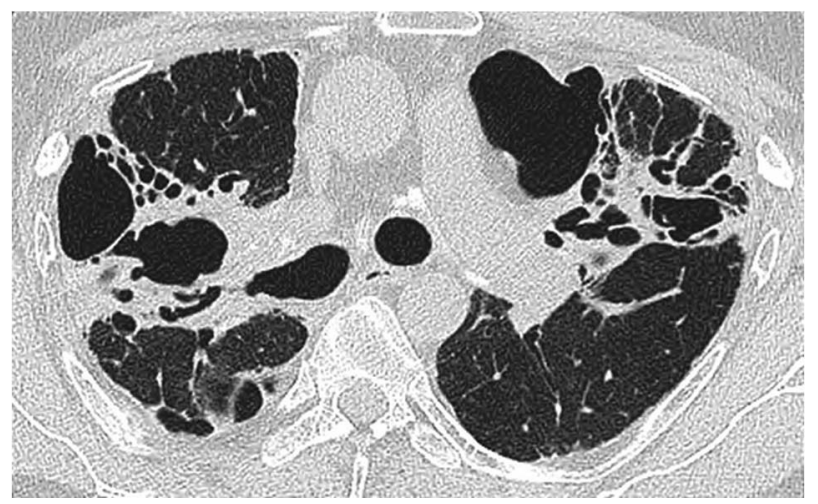

Figure 1 Thin section CT through the upper lobes of a 49 year-old male showing (A) peri-hilar fibrocavitary disease and several calcified hilar and mediastinal lymph nodes consistent with the diagnosis of sarcoidosis. In a cavity adjacent to the right hilum there is a fungus ball with associated subpleural consolidation. Eleven months later (B), following six cycles of caspofungin, the fungus ball is no longer present and the consolidation around the lateral aspect of the cavity (and around the left hilum) has diminished. between 2008 and 2012. Nine patients were treated with oral triazoles (itraconazole $\mathrm{n}=5$, voriconazole $\mathrm{n}=4$ ) for a minimum of 4 months (up to 24 months) prior to caspofungin. Nine patients were receiving prednisolone (median dose $12.5 \mathrm{mg} /$ day; range 7.5-20 mg), with four patients receiving additional immunosuppressive therapy (methotrexate $\mathrm{n}=1$, azathioprine $\mathrm{n}=3$ ). High-resolution CT (HRCT) demonstrated destructive fibrocavitary pulmonary changes (including aspergilloma) in all patients (figure 1). Detailed patient information (including treated disease course) is summarised in the online supplement. gressive pulmonary fungal disease (including weight loss) in seven patients and triazole intolerance (rash, hair loss) in two patients. In the 12 months prior to casporespiratory symptoms (including recurrent haemoptysis in six patients), with deteriorating HRCT imaging in nine patients. Lung function deteriorated in seven patients, with a reduction in median total lung diffusion for carbon monoxide
Caspofungin was initiated due to profungin, all patients reported worsening
(DLco) from $42 \%$ (range 33-73\%) to $34 \%$ (range 24-70\%) $(p=0.05)$ and a trend downward in spirometric lung volumes. Five patients lost weight $(3-6 \mathrm{~kg})$, and three patients were underweight (body mass index (BMI) 15.5-19.0) at the time caspofungin was commenced.

Caspofungin infusions were repeated every 12-16 weeks, with maintenance itraconazole $(n=6)$ or voriconazole $(n=4)$ between infusions. During a median follow-up of 16.5 (1-32) months, patients received between one and nine (median of six) cycles of caspofungin. Immunosuppression (including prednisolone) remained unchanged. In nine patients, symptoms (including haemoptysis) and inflammatory markers improved rapidly, with a decrease in median $\mathrm{C}$ reactive protein (CRP) from 31 (range 3-94) to 15 (range 3-23) ( $\mathrm{p}=0.02)$ within 3 months, and sustained improvements in CRP at 6 months (CRP 4; range 1-14) and 12 months (median CRP 11; range 6-14). BMI normalised in two patients (with weight gain of $6 \mathrm{~kg}$ and $9 \mathrm{~kg}$ ) and remained low (although improved) in one patient. In contrast with previous deterioration, HRCT appearances (assessed blinded to treatment) improved in four patients and remained stable in three. In two patients who did not undergo repeat HRCT, repeat chest radiographs stabilised. Follow-up imaging was unavailable in one patient, who died 1 month after caspofungin was commenced. In contrast with deteriorating pulmonary function tests in the 12 months prior to caspofungin, median forced vital capacity and DLco stabilised in the 12 months following caspofungin (see online supplementary table S1). Two patients died during follow-up (of progressive respiratory failure after 4 weeks and cor pulmonale after 32 months).

CPA in sarcoidosis is notoriously difficult to treat and is often associated with a dismal long-term prognosis. Our results suggest that caspofungin may offer a safe and effective therapy in patients with sarcoidosis and progressive CPA.

Gregory J Keir, Benjamin Garfield, David M Hansell, Michael R Loebinger, Robert Wilson, Elisabetta A Renzoni, Athol U Wells, Toby M Maher

Royal Brompton Hospital, London, UK

Correspondence to Dr Toby M Maher, Interstitial Lung Disease Unit, Royal Brompton Hospital, Sydney Street, London SW3 6NP, UK; t.maher@rbht.nhs.uk

Contributors GJK, BG and TMM performed data collection, analysis and prepared the manuscript. MRL, RW, EAR and AUW were involved in patient care, contributed to and reviewed the final manuscript. DMH provided radiology input and reviewed the final manuscript. GJK acts as guarantor for overall content of the manuscript. 


\section{Competing interests None.}

Ethics approval Brompton, Harfield \& NHLI research ethics committee (REC ref 01-246).

Provenance and peer review Not commissioned; externally peer reviewed.

- Additional material is published online only. To view please visit the journal online (http://dx.doi.org/10. 1136/thoraxjn-2013-203988).

To cite Keir GJ, Garfield B, Hansell D M, et al. Thorax 2014;69:287-288.
Received 6 June 2013

Revised 18 August 2013

Accepted 22 August 2013

Published Online First 12 September 2013

Thorax 2014;69:287-288.

doi:10.1136/thoraxjn-2013-203988

\section{REFERENCES}

1 Denning DW, Pleuvry A, Cole D. Global burden of chronic pulmonary aspergillosis complicating sarcoidosis. Eur Resp J 2013;41:621-6.

$2 \mathrm{Nam} \mathrm{HS}$, Jeon K, Um SW, et al. Clinical characteristics and treatment outcomes of chronic necrotizing pulmonary aspergillosis: a review of 43 cases. Int J Infect Dis 2010;14:479-82.

3 Felton TW, Baxter C, Moore CB, et al. Efficacy and safety of posaconazole for chronic pulmonary aspergillosis. Clin Infect Dis 2010;51:1383-91.

4 Sambatakou H, Dupont B, Lode $\mathrm{H}$, et al. Voriconazole treatment for subacute invasive and chronic pulmonary aspergillosis. Am J Med 2006;119:17-24.

5 Kravitz JN, Berry MW, Schnabel Sl, et al. A modern series of percutaneous intracavitary instillation of amphotericin B for the treatment of severe hemoptysis from pulmonary aspergilloma. Chest 2013;143:1414-21. 